\title{
Listserv Lemmings and Fly-brarians on the Wall: A Librarian-Instructor Team Taming the Cyberbeast in the Large Classroom
}

\section{Ruth Dickstein and Kari Boyd McBride}

\begin{abstract}
Computer technologies, in both the library and the classroom, have the potential to serve the aims of liberatory pedagogies, especially when used creatively to empower students in the shared construction of knowledge. However, such empowerment can happen only if students are given the tools to find their way through the ever-increasing complexity of print and online resources. This article shows how a reference librarian and a faculty member can team up effectively to teach research strategies and critical thinking skills (including analysis and evaluation of resources, so necessary for the Internet) in a large classroom through careful use of a list (e-mail forum) and focused research assignments. Such strategies revolutionize the ways that reference librarians do their work, greatly increasing their interaction with students by overcoming students' reluctance to seek help and their fear of computerized resources. Librarian, instructor, and student become partners in the creation, evaluation, and dissemination of scholarly information.
\end{abstract}

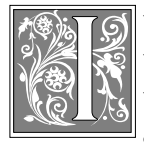

t now is a commonplace that technology is changing forever the way we educate students and, thus, altering our jobs as university librarians and teachers. Library reference rooms do not resemble those of even a decade ago, and classrooms too are defined increasingly by cables and video screens rather than by books and chalk. Many educators are scrambling to assess the significance of these profound changes in education, questioning what we accomplish with our commitment (or, some would say, servitude) to computer technology in the classroom. ${ }^{1}$ Although the Luddite in us all decries the dehumanizing effects of technologies that have the potential to further divide class from class, student from mentor, and seeker from knowledge, many also hold out the hope that instructional computer technologies can serve the aims of critical, liberatory, and feminist pedagogies by empowering students to be confident users of these new resources which certainly will control access to information of all

Ruth Dickstein is the Reference Librarian in the Main Library at the University of Arizona; e-mail: dickstei@bird.library.arizona.edu. Kari Boyd McBride is a Lecturer in the Women's Studies Department at the University of Arizona; e-mail: kari@u.arizona.edu. 
sorts in the years to come. These pedagogies also have the potential to invite students into the process of knowledge construction, encouraging them to play active roles in determining the directions such technologies take us. In the meantime, we all are learning as we go, trying not to overgeneralize from our particular experiences with computer instruction, while seeking to discern in those contexts and in the insights of other educators the thread of understanding that will lead us through the maze of possibilities and problems offered by the Information Age.

The authors of this article are a librarian and an instructor who teamed up to use computer technology to enhance teaching and learning in the classroom and the library. Their university has a large research library with more than four million volumes and a large collection of maps, government documents, microforms, video and films, music, and manuscripts. ${ }^{2}$ The library is becoming increasingly computerized and has more than sixty CD-ROM indexes as well as access to a dozen periodical indexes on its online catalog. The reference room in the Main Library has fifty-six computers devoted to Web access and many others for searching the online catalog and the CD-ROM databases.

The proliferation of such technology is bringing together instructors and librarians more and more. ${ }^{3}$ Last year, the authors cowrote an article on using an email forum (a listserv) in a small upperdivision class, Feminist Theories, suggesting how increased communication among students, between students and teacher, and between students and librarian might emerge through listserv-mediated assignments. ${ }^{4}$ It was found that instructional computer technologies can serve critical and feminist pedagogies by realizing postmodern epistemologies which assume that knowledge is not static or preexistent but, rather, is always situated, always partial, always dynamic. ${ }^{5}$
The wired classroom can help to model these empowering insights by making students active participants in the construction of knowledge. Since that first experience of computer-mediated partnership, the authors have continued to develop online pedagogies, using listservposted assignments in a series of large classes where, it was very quickly learned, different rules apply. The women's studies courses Introduction to Women's Studies and Women and Western Culture (http:/ / www.u.arizona.edu/ $\sim$ kari/ws200.htm) ${ }^{6}$ were the laboratories for an elaboration of the teacher-librarian team relationship and lots of insight into how differently a teaching tool such as a listserv works when the class is large rather than small and is filled with general-interest students rather than women's studies majors.

\section{Learning the Hard Way}

As before, the authors set up an e-mail discussion list for each class, with the librarian as well as the instructor joining all lists. Though the two syllabi were quite different, students in all three sections were expected to contribute one short reflection on assigned readings or to report on a small research project every week or two. With forty to fifty students in each of three sections, the volume of e-mail quickly became overwhelming for all involved. The librarian, who also was on two other class lists, had to sign off periodically just to survive. By midsemester, it became clear that students were not reading each other's postings, eliminating one of the benefits of listserv assignments: They allow all class participants to read student contributions rather than the teacher only. Also, where the instructor had been able to respond to many individual student postings in a small class, encouraging students to probe more deeply and nurturing the kind of conversation that turned out to be so fulfilling for everyone involved, with three large sections to oversee, she was overwhelmed by the task of 
simply grading the assignments. Little spontaneous conversation developed until near the end of the semester when one of the sections took up the topic of gays and women in the military, and about fifteen students carried on a lively debate for more than a week. The failure of the listserv medium to insure such freewheeling exchange was disappointing but appears to be an inevitable outcome in a large class. Further restraining such conversation is the fact that students these days increasingly find themselves on multiple lists, often for two or more classes, which limits the time they are likely to devote to gratis chatting on any single list.

The sheer volume of e-mail messages also contributed to a pedagogical disaster in one section in which almost every student failed to fulfill the terms of an assignment. Students in Women and Western Culture had completed a unit on early modern interaction between Europeans and the peoples of the Americas, drawing on Mary Louise Pratt's concept of the "contact zone" to think about how notions of race, class, gender, nationality, and religion become sharply defined when cultures collide. ${ }^{7}$ Their assignment at the end of the unit was to post an analysis of how "women," "western," and "culture" interact to construct a dominant male authorial identity in John Donne's elegy Going to Bed. The instructor had read the poem in class, explaining difficult terms and images, and had discussed the assignment. Students in both sections had seemed to understand their task. However, at least one student in one of the sections ignored the assignment to analyze the cultural dynamics of the poem and, instead, contributed a scathing denunciation of Donne's misogyny. Overwhelmed by the number of messages pouring into her e-mail box, the instructor failed to use the student's misunderstanding as an opportunity to restate and elaborate on the assignment for the rest of the class-a serious error. Instead, within a day, most of the other students in that section had followed the lead lemming over the precipice into academic suicide. (The knowledge that, at least in the case of this assignment, students were reading each other's postings proved small consolation for the disaster.) Some defended Donne's attitudes toward his mistress (he was in love, the poem is typical of the era), most lambasted him (he was an adulterer, a predator, an unreconstructed male sexist pig), but almost all of them ignored the assignment and took up cudgels in a misplaced war of the sexes. These were "listserv lemmings," for such mass failure to fulfill the terms of the assignment never would have occurred had students been turning in analyses directly to the instructor. In fact, students in the other section of the course did very well with the assignment; they may even have benefited from reading each other's postings, as students often do in the context of listserv communication-the flip side of the lemming phenomenon.

\section{The sheer volume of e-mail messages also contributed to a pedagogical disaster in one section in which almost every student failed to fulfill the terms of an assignment.}

The day of the lemmings proved a significant lesson about the importance of staying engaged with list discussions. When the phenomenon began to emerge a second time, in the Introduction to Women's Studies class, the librarian and the instructor were prepared. Students in that class were studying global women's movements. ${ }^{8}$ Each week, selected students were assigned the role of historian or journalist to report on the history of women's status or women in current events in a particular country. The week that the history of women in the Occupied Territories (Gaza and the West Bank) was studied, students doing the historian 
assignments began a lemminglike stampede toward the cliff in their misunderstanding of the term Palestinian. They had begun their research using the keyword "Palestine" and were finding information about women in ancient Israel under the Levitical code or about women's contribution to the founding of modern Israel. One notable entry provided an extensive biography of Golda Meir. Fortunately, past experience with listserv lemmings confirmed that the librarian and the instructor needed to act quickly to avert disaster. Both posted detailed entries to the list, explaining the complex historical relationship between Judaism, Christianity, and Islam, and recounting the history of Arab-Israeli relations since the 1940s. In addition, a colleague generously provided up-to-date insights into the lives of her Palestinian relatives living in the Occupied Territories. For most students, this information put them back on track. Indeed, it became clear very quickly who was reading listserv postings and who was declining to participate in that portion of the class exchange.

\section{Fortunately, past experience with listserv lemmings confirmed that the librarian and the instructor needed to act quickly to avert disaster.}

Both librarian and instructor had, of course, anticipated that students would need ongoing librarian support researching the status of women in various countries, as would the students in the Women and Western Culture sections, who were producing Web sites on the history of women and the West. In all three sections, students had been introduced to the librarian early in the semester when she made a presentation on using online research tools. It very quickly became clear, however, that providing students with this kind of information before they actually needed it was only the first step; the essential second step was to follow up with "point-of-need" information, that is, information tailored to specific student queries or problems, the kind of assistance that a lurking librarian —an online reference librarian listening in to students' listserv assignments—could provide.

\section{The Lessons Learned}

Successful librarian listserv interaction with students seemed to occur in a number of situations. First and most frequently, the librarian observed that students had an information need and were floundering as they tried to complete assignments on their own using whatever resources they came across, however inappropriate to the task. Their listserv entries would begin with the disclaimer that "This was the only article I could find on [assigned topic]." One noted instance of this happened in the Women and Western Culture course when students were required to post their research topics and summarize the research questions they intended to investigate. One student expressed interest in doing a report on the Comfort Women enslaved by Japanese soldiers during World War Two. Although Korean women had received the most media attention, the student, who was from Taiwan, knew that Taiwanese women also had been involved but did not know how to find information on the topic. This was an open invitation to the librarian to make a few suggestions about how to search the Web as well as CDROM indexes such as Sociofile for pertinent information. In another instance, several students submitted listserv postings recounting their difficulty finding books on their chosen research topics. The librarian used this as an opportunity to explain the difference between searching the online catalog by keyword and subject headings and how to use a keyword search to find a subject heading. By using the student's chosen topic, "witchcraze," as an example, the librarian explained that, although "witchcraze" was not a subject heading, a keyword 
search would lead the student to the heading "witchcraft-Europe," and that a subject search under this heading would identify nineteen books on the topic. Such opportunities to provide point-of-need information emerged repeatedly, allowing her many more opportunities to interact with students than she would ever have had were she simply waiting for them to show up at the reference desk.

Another category of librarian-student interaction emerged as students became increasingly aware of the possibilities afforded by the librarian's presence on the class listserv and began to e-mail her directly with research questions. When more than one student asked similar questions, the librarian used the listserv to teach the whole class at once. For instance, after being contacted privately by two groups about finding biographical information on women, the librarian shared suggestions on the class list, including a discussion of effective subject headings, titles, and call numbers of the best biographical resources on women and instructions on using biographical CDROMs available in the library. Because this seemed to be an area of common interest, the librarian then developed a Web page on the topic for students to use in future research. ${ }^{9}$

These "lurking librarian" exchanges were invaluable, but the authors realized that students' lack of preparation to do college-level library research would only increase as the number of computer-mediated resources continued to proliferate. Furthermore, the explosion of the Internet intensifies students' research problems in a particular way: The lack of scholarly oversight on the Internet means that students must be equipped to assess the authority of the articles and information they encounter there (a task that is done for them, to a certain extent, by university librarians and editors of journals and books). Therefore, when the authors assessed the first semester's experiences using a list in a large class, it was decided to combine the need to limit student postings with the implementation of assignments that would teach students how to do research in a variety of media and how to evaluate what they found. The result was the Listserv Research Report (http:/ / www.u.arizona.edu/ kari/listrep.htm). The instructor was again teaching two sections of Women and Western Culture. Each class had been divided into six groups of between four and eight students. The two sections shared an e-mail list, and one group reported each week (for a total of twelve weeks, beginning the third week of the class) on an assigned topic related to the week's readings. This limited use of the listserv did not aim to foster the kind of continuous classroom exchange possible in a smaller class; students were not expected to contribute to the list each week but merely to read the half-dozen or so postings contributed by the group of the week. Conversations would occasionally explode onto the list- the coming-out episode on the television program Ellen, for example, sparked an impassioned series of postings-but such exchange was not part of the course expectations.

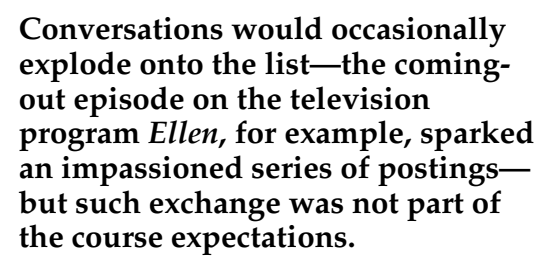

Revising the goals for the listserv helped the authors to create an assignment that was workable for students, instructor, and librarian alike, one that resulted in successful research and reporting for most students. The Listserv Research Report stipulated that each group of students would consult a variety of resources, one student per source (reference work, resource found using a CDROM index, journal article, book, and Internet site), on the assigned topic. (The 
way the assignment combines course content with research skills is another way that point-of-need information is provided:Students are not asked to learn research techniques until they need them to fulfill an assignment.) The librarian again had given students a computer lab introduction to the library's online catalog and the Internet. This time, a day was added in the library for students to begin their exploration of various resources, with special assistance using CD-ROM indexes. The librarian also provided students with a list of key reference sources to use for their assigned topics.

The fact that students were asked to evaluate the resources they found made them much more effective users of the Internet. And the librarian continued to be the "fly-brarian" on the listserv wall, responding quickly when students recounted research problems. One memorable posting provided her with an opportunity to explain Boolean operators and search engine logic (if there is such a thing) and to comment on the reality of what kinds of Web materials emerge when one searches for women-related topics. The student posting began:

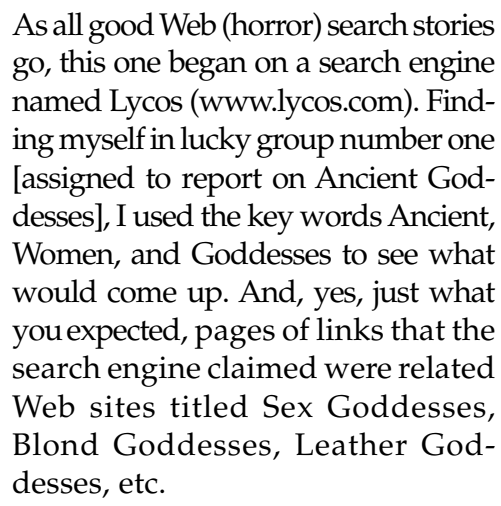

This narrative provided the perfect opportunity for the lurking librarian to interrupt and explain how Lycos had assumed the "or" operator and how to change the search commands in Lycos. On a later occasion, the librarian was able to teach students how to use the plus sign $(+)$ and quotation marks in other search engines. Despite her initial frustration, the student was ultimately successful in finding a good site at the University of Virginia which gave her some confidence in the trustworthiness of the information. But her evaluation of the Web as a resource was on target when she concluded that although the Web had some good resources for academic research on "classical" goddesses, there was an absolute lack of information on non-Greek goddesses. "The Greeks weren't the only ones with fabulous goddesses that helped shape cultures, myths, and religions. There are Hawaiian, Celtic, Native American, Hindi, and other Pacific Islander goddesses...." However, a search for these goddesses did not prove fruitful, and she concluded that "The World Wide Web is heavily slanted towards modern material . . . . Once in a while, you can find a site that makes it worthwhile."

An unexpected bonus of this assignment was the way that students became critical users of more traditional resources. Not only did they select better Web sites and critically assess Web sources, but they also applied the same critical skills to reference materials, journal articles, and books. One student assigned to research women in early Christianity remarked that the article she read in the Women's Studies Encyclopedia ${ }^{10}$ assumed that the reader was not only well read in religious topics but well read in general: "If you can get past all the highfalutin words and really get the ideas that this article attempts to present, I would recommend its use as a reference source." This student further questioned why all the sources cited in the references were written by men: "Were there no women, past or present, who could have shed a little light on their own history?" She also noted that content and form varied from article to article and commented on the lack of editing consistency that would have required each piece to be ac- 
cessible to the nonspecialist user for whom this work was written. In other words, she had identified a significant weakness in this particular reference work. Another student used the Handbook of American Women's History ${ }^{11}$ to research "women, industrialization, and immigration." She shared on the list that "Though the original idea of having to use a reference work seemed unappealing and impossible, this work was actually quite informative and a valuable source.... This would be a great place to START [her caps] research, but could hardly be used for a more thorough paper." A librarian could not have stated it more precisely. In short, this was one of the most successful assignments the instructor had given in twelve years of teaching and perhaps the librarian's most successful engagement with students as a reference librarian: Students became critical readers and thinkers, and had learned some essential tools of academic research.

The students' final project for the Women and Western Culture course was to create a group Web site, an assignment that required them to continue sharpening their research and assessment skills. Although the excellence of the projects varied, of course, a large number of students were able to build on their scholarly skills to produce important contributions to Internet resources. For example, the site Women and Slavery (http:/ /www.blarg.net/ sunstar/ws200/slavery.htm) covers that topic better than any existing site (and has become a required course reading as a result). The librarian-instructor collaboration continued by grading the web site assignments together, reserving a day in a computer lab with the course teaching assistants to assess and critique the students' projects.

An added bonus to the teamwork emerged when students (who had indicated early in the course that they were either reluctant to approach librarians for help or unwilling to make the trip to the library when assistance was needed later) commented on how essential it had become to have a librarian on the list and available by e-mail for individual consultation. Indeed, the librarian is finding that her reference work transpires increasingly via e-mail, especially as essential reference tools take both paper and electronic forms these days. The e-mail reference exchange continues to supplement the traditional desk encounter, with the librarian's postings providing broader instruction as well as answers to specific questions. And students from these initial women's studies courses continue to contact their "flybrarian" for reference help in other classes. They have learned (to their relief, no doubt) that they are not expected to know how to find everything, that it is perfectly acceptable to ask for help

Thus, even though some of their initial enthusiasm for listservs was dampened by the exigencies of the large class and the increased volume of e-mail generated by multiple classes, the authors continue to find listservs to be valuable resources for progressive pedagogiesand in ways they never expected. Even though the amount of unsolicited discussion on the list decreased, the forum was still available when students needed to bring important current issues to the class. Listservs are still the best way to share responsibility for learning and the production of knowledge in the large class. And, perhaps most important of all, listservs provide the best medium for realizing the potential of librarian-instructor collaboration, through both casual "lurking" and very focused assignments such as the Listserv Research Report. The multiplicity of interactions made possible by an e-mail forum begins to realize the promise of critical pedagogies to empower librarian, teacher, and student as effective partners in the creation, evaluation, and dissemination of information. 


\section{Notes}

1. Two recent collections discuss the use of new technologies in higher education, covering a broad range of issues and experiences. The 1996 Mid-South Instructional Technology Conference addressed issues surrounding technology and pedagogy, including distance learning, library support, faculty support, and technology-based facilities. American Association of Higher Education, Mid-South Instructional Technology Conference: Proceedings (1st, Murfreesboro, March 31April 2, 1996) (Murfreesboro, Tenn.: Middle Tennessee State Univ., 1996). ERIC ED 400790.

A May 5, 1997, posting on the American Association for Higher Education listserv (aahesgit@list.cren.net) included twenty-two examples of comparative studies in which the Internet was used for part or all of a course. The brief descriptions direct readers to URLs where full information on the studies may be found.

2. Dickstein's Women's Studies on the Internet organizes material for researchers in the field (http://dizzy.library.arizona.edu:80/users/dickstei/homepg.htm).

3. See, for instance, William D. Graziadei and Gillian M. McCombs, "Wiring the Trenches: Teaching Faculty and Librarians Working Together on the Internet," Internet Reference Services Quarterly 1 (1) (1996): 89-103. ACRL has always supported the role of academic librarians as partners with teaching faculty in the educational enterprise. Draft guidelines state that "The teaching that is most characteristic of academic librarianship involves instructing people in becoming independent scholars who can find, assess, and use information resources effectively." ACRL Institution Priorities and Faculty Rewards Task Force, "The Redefining Scholarship Project: A Draft Report," College \& Research Libraries News 58 (June, 1997): 415. ACRL goals to redefine librarians' scholarly activities incorporate Ernest Boyer's expanded definition of scholarship. Ernest Boyer, Scholarship Reconsidered: Priorities of the Professoriate (Princeton, N.J.: Carnegie Foundation for the Advancement of Teaching, 1990).

4. Kari Boyd McBride and Ruth Dickstein "Making Connections with a Listserv," Computers $\mathcal{E}$ Texts 12 (July 1996): 7-11 (http://info.ox.ac.uk/ctitext/publish/comtxt/ct12/mcbride.html). Many other authors have discussed the use of class listservs. See Robert M. Bender, "Creating Communities on the Internet: Electronic Discussion Lists in the Classroom," Computers in Libraries 15 (May 1995); and Christopher Stephens, "E-mail Lists—Virtual Lite," Internet Teaching (Feb. 3,1996) (http://info.ox.ac.uk/jtap/reports/teaching/email.html). The experiences of several instructors at the University of North Carolina-Chapel Hill, are summarized in an online newsletter published at UNC-CH: Online Discussion, New Chalk 1 (Feb. 24, 1997) (http:/ / www.unc.edu/ courses/newchalk/archive/ncv1n7.html).

5. Gaziadei and McCombs argue that "As a result of the use of technology in education, the traditional roles of teacher and librarian are being questioned" ("Wiring the Trenches," 95). But, in fact, pedagogical theory questioning the role of the teacher (and, by implication, the librarian) preceded the availability of instructional computer technologies by decades (and the epistemological theories on which such pedagogies are based date to the nineteenth century). Paolo Friere's seminal work, Pedagogy of the Oppressed, trans. Myra Bergman Ramos (New York: Continuum, 1970), spawned a host of liberatory, critical, and feminist pedagogies.

6. For a description of the course rationale and structure of this online syllatext or hypertextbook, see Kari Boyd McBride, "Tailoring the Textbook to Fit the Student Body," Computers \& Texts 14 (1997) (http://info.ox.ac.uk/ctitext/publish/comtxt/ct14/mcbride.html).

7. Mary Louise Pratt, "The Arts of the Contact Zone," Profession 1991: 33-40.

8. The authors used: Amrita Basu, The Challenge of Local Feminisms: Women's Movements in Global Perspectives (Boulder, Colo.: Westview Pr., 1995).

9. "Who Was She?: Finding Biographical Information About Women" (http:// dizzy.library.arizona.edu:80/users/dickstei/WHO.HTM). From time to time, discussion on the listserv coincided with information appearing on other lists to which the librarian subscribed. About the same time, one class was addressing the Disney portrayal of Pocahontas, a discussion of the Disney portrayal of Snow White was occurring on WMST-L, an academic women's studies list. The librarian shared this discussion with the class, as many of the issues raised about the portrayal of heroines mirrored each other. Also, during that semester, some students raised questions about the ongoing election (some as basic as "How do I register to vote?"). The librarian used this as an opportunity to forward postings from online news reports from Women Leaders Online (http://www.wlo.org), which frequently contained information on political issues not covered by the mainstream press.

10. Helen Tierney, ed., Women's Studies Encyclopedia, 3 vols. (New York: Greenwood, 1989-1990).

11. Angela Zophy and Marie Howard, eds. Handbook of American Women's History (New York: Garland, 1990). 